\title{
Recognition and recall by children and adults as a function of variations in memory encoding instructions*
}

\author{
JAMES W. HALL and JEAN W. PIERCE \\ Northwestern University, Evanston, Illinois 60201
}

\begin{abstract}
In four experiments $\mathrm{Ss}$ were instructed to learn a set of 40 words by producing implicit associative responses to each item (association instructions), by repeating items over and over (repetition instruction), or by using their own devices (neu tral instructions). Experiment I showed that recognition memory (RM) accuracy was greatest under association instructions for adults and children and least under repetition instructions for children. The implications of these results for a frequency theory analysis for RM were discussed. Experiments II, III, and IV examined free recall (FR) as a function of encoding instructions at short $(1 \mathrm{~min}$ ) and long (either $90 \mathrm{~min}$ or $24 \mathrm{~h}$ ) retention intervals. FR was worst under repetition instructions, with little overall difference between the association and neutral conditions. However, in Experiments III and IV, using school children, the neutral condition exceeded the others in FR after $90 \mathrm{~min}$ but not after $1 \mathrm{~min}$.
\end{abstract}

The series of experiments reported in this paper were generated by a concern with the effectiveness of variations in memory encoding operations on the recognition and recall of verbal material. Underwood $(1969 \mathrm{a}, \mathrm{b})$ has proposed that a memory for verbal material be conceived as a set of attributes of that material that is stored in some fashion. Memory encoding, then, consists of the storage of such attribute information. A number of different attributes were delineated by Underwood, including the verbal associative attribute. There is considerable evidence that verbal associations are produced, mainly as implicit responses (implicit associative responses or IARs), during encoding by adults (Underwood, 1965; Kimble, 1968; Anisfeld \& Knapp, 1968) and by children as young as 3 years of age (Hall \& Halperin, 1972). That evidence derives mainly from recognition memory (RM) experiments in which "new" recognition test items that are associates of to-be-remembered items are falsely recognized more frequently than are items unrelated to the to-be-remembered items. What has not been determined are the consequences of such IAR occurrence. That is, it is not clear whether variations in the occurrence of IARs during encoding are related to subsequent recognition or retrieval processes. The experiments reported here attacked this question by examining the effects of memory encoding instructions on RM (Experiment I) and on recall (Experiments II, III, and IV).

\section{EXPERIMENT I}

In the main, Experiment I constituted a replication of an earlier RM study. In that earlier experiment (Hall,

*We are indebted to Illinois School District 65 in Evanston, and particularly to Ida Lalor, Corrinne Shumaker, and the teachers and students of the Martin Luther King Laboratory School in Evanston. Thanks are also due Benton J. Underwood for his helpful comments on the manu script.
1969), children were presented a list of to-be-remembered items under one of three sets of instructions: (1) instructions to produce IARs to presented items (the association condition), (2) instructions to repeat presented items and suppress other activities (the repetition condition), and (3) instructions to remember the words as best they could (the neutral condition). A subsequent recognition test showed that false recognitions of associates relative to unrelated (control) words were most frequent for the association condition and least frequent for the repetition condition. That is, such instructions evidently were effective in modifying the extent to which the verbal associative attribute was employed during encoding. The three conditions did not differ reliably in correct recognitions in that study, although such an effect may have been masked by the relatively low difficulty level of the task.

There were two major objectives in conducting Experiment I. First, we wished to be quite confident that the variations in encoding instructions in fact produced the variations in encoding activity indicated by the results of the previous experiment by Hall (1969) and that such an effect obtained for adults as well as children. Replication of the sort of false recognition data obtained in that earlier study would provide that confidence and set the stage for studies examining the effects of these variations on FR. Second, by increasing task difficulty in relation to that earlier experiment, Experiment I would be more sensitive to possible effects of the encoding variations on RM. Such effects possibly have been obscured by a ceiling effect in the earlier study. It seemed particularly important to test most adequately for effects of the encoding variations on recognition accuracy, in view of recent applications of frequency theory (Ekstrand, Wallace, \& Underwood, 1966) to the RM situation (e.g., Underwood \& Freund, 1968). According to that analysis, the recognition 
Table 1

Word Lists

\begin{tabular}{|c|c|c|c|c|c|c|c|}
\hline \multicolumn{4}{|c|}{ List 1} & \multicolumn{4}{|c|}{ List 2} \\
\hline Word & Function & Word & Function & Word & Function & Word & Function \\
\hline $\operatorname{man}$ & F & saddle & CS & telephone & F & tree & A \\
\hline pickle & $\mathrm{F}$ & table & $\mathrm{CS}$ & monster & $\mathrm{F}$ & boy & 0 \\
\hline shoe & $\mathrm{F}$ & come & 0 & quickly & 0 & happen & $\mathrm{O}$ \\
\hline snow & $\mathrm{F}$ & rose & CS & dog & A & month & 0 \\
\hline read & 0 & drink & $\mathrm{CS}$ & nose & $\mathrm{R}$ & Monday & 0 \\
\hline trout & CS & loud & 0 & doctor & $\mathrm{U}$ & doubt & $\mathbf{R}$ \\
\hline bed & $\mathrm{CS}$ & fingers & 0 & music & $\mathrm{U}$ & brush & $\mathbf{U}$ \\
\hline lamp & CS & lion & 0 & brother & 0 & sleep & A \\
\hline cook & $\mathrm{CS}$ & eagle & $\mathrm{CS}$ & cut & A & coffee & $\mathbf{U}$ \\
\hline ford & CS & hammer & 0 & chair & A & flower & A \\
\hline quickly & 0 & month & 0 & gun & 0 & friend & $\mathbf{U}$ \\
\hline salt & CS & oak & CS & door & $\mathrm{U}$ & read & 0 \\
\hline dollar & CS & boy & 0 & lion & 0 & camp & $\mathbf{R}$ \\
\hline spider & 0 & happen & 0 & label & $\mathbf{R}$ & spider & 0 \\
\hline never & 0 & peach & $\mathrm{CS}$ & numbers & 0 & life & $\mathbf{R}$ \\
\hline brother & 0 & gun & 0 & bird & $\mathbf{A}$ & light & A \\
\hline poodle & $\mathrm{CS}$ & king & $\mathrm{F}$ & fault & $\mathrm{R}$ & rooster & $\mathbf{U}$ \\
\hline knife & CS & between & $\mathrm{F}$ & city & $\mathrm{U}$ & water & A \\
\hline Monday & 0 & brick & $\mathrm{F}$ & cry & $\mathrm{U}$ & money & $\mathrm{A}$ \\
\hline \multirow[t]{2}{*}{ numbers } & 0 & on & $\mathrm{F}$ & rug & $\mathrm{U}$ & play & $\mathbf{U}$ \\
\hline & & & & legal & $\mathbf{R}$ & beach & $\mathbf{R}$ \\
\hline \multicolumn{4}{|c|}{$F=$ Filler Word } & south & $\mathrm{U}$ & fruit & $\mathbf{A}$ \\
\hline \multicolumn{4}{|c|}{$\mathrm{O}=$ Old Word } & food & A & fingers & $\mathrm{O}$ \\
\hline \multicolumn{4}{|c|}{$\mathrm{CS}=$ Critical Stimulus Word } & noodle & $\mathbf{R}$ & hammer & $\mathrm{O}$ \\
\hline \multicolumn{4}{|c|}{$\mathbf{R}=$ Rhyming Word } & coke & $\mathbf{R}$ & car & A \\
\hline \multicolumn{4}{|c|}{$\mathbf{A}=$ Associate } & horse & A & job & $\mathbf{U}$ \\
\hline \multicolumn{4}{|c|}{$\mathrm{U}=$ Unrelated Word } & clown & $\mathbf{U}$ & said & $\mathbf{R}$ \\
\hline
\end{tabular}

decision is made on the basis of a perceived situational frequency that accumulates through perceiving and rehearsing the items. Thus, one might expect instructions to repeat items again and again (the repetition instructions) to facilitate recognition relative to the other two instructional conditions.

Finally, the design of the present experiment was expanded so that the recognition test contained new words selected because of their apparent acoustical similarity to the to-be-remembered items.

\section{Method}

Subjects. The children who served as the Ss in Experiment I were 42 third graders and 42 fourth graders selected randomly from all third and fourth graders in attendance at the Martin Luther King Elementary School in Evanston, Illinois. These children represented a wide range in terms of socioeconomic backgrounds. Also included as Ss were 110 students enrolled in an introductory psychology class at Northwestern University.

Design and Procedure. At each age (grade) level, the Ss were assigned randomly to three group which differed only in terms of the instructions given prior to presentation of the to-be-remembered item s (List 1 in Table 1). For one group (the association condition), the Ss were told to think of words of which the presented words reminded them, and several appropriate examples were given. The examples were constructed to emphasize that several IARs could be produced. The second group (the repetition condition) was told to repeat each presented item over and over, thinking of nothing else until the next item was presented. The third group (the neutral condition) was merely told to try to remember the items as best they could.

The items presented for learning are shown in the order of presentation as List 1 on the left in Table 1 and those comprising the test list are shown on the right side of that table. All presentation was auditory, using a tape recorder. The to-be-remembered items were presented at a $4-\sec$ rate, and $1 \mathrm{~min}$ intervened between the learning and the test list. The test items were presented at a 5 -sec rate. The task was administered individually with the children and recognition decisions were given orally. For adults the task was administered in small groups and responses were given by marking "old" or "new" on an answer sheet. Also, at the conclusion of the session, the adult Ss were asked to describe their rehearsal activities.

The logic of the experiment can be described most clearly by considering the recognition test items in relation to the items presented for learning. The test list included 16 old words, or words that had been presented on the learning list, and 16 unrelated words, or new words not included on the learning list. Two other important categories of test list items were associates of previou sly presented "critical stimulus" items and words that rhymed with these same 16 items. Thus, for each of the 16 critical stimulus items shown in Table 1 (e.g., TROUT), there were two related items in the recognition test, namely, an associate (e.g., FISH) and a thyming word (e.g., DOUBT). Also included at the beginning of the test list were two filler items, bringing the total to 66 items on the test list. The learning list included, in addition to the 16 repeated words and the 16 critical stimulus words, four filler words placed at the beginning and four at the end of the list, for a total of 40 items. These various classes of words are labeled and shown together in Table 1. The order of presentation of the two lists was determined randomly (except for placement of the filler items) and was identical for all $S s$ in this and the subsequent experiments.

\section{Results and Discussion}

The data from Experiment I are summarized in Table 2. The pattern of results shown there for the 
children replicated the results of the study described earlier (Hall, 1969), in that false recognitions of associates in relation to unrelated words were substantially greater under associative instructions than under neutral instructions and substantially less under repetition than under neutral instructions. For the adult Ss, the pattern was somewhat different. Here the associative and neutral conditions were nearly identical in this respect, with the repetition condition markedly lower. These differing patterns for adults and children were reflected in a highly significant triple interaction of Age by Instructions by Error Type (associates vs unrelated words) $[F(2,188)=9.86, p<.001]$. No differences between false recognition frequencies for the rhyming and unrelated words were found at either age level or under any instructional condition.

To examine the general RM accuracy data, $d^{\prime}$ scores were derived from performance on old and on unrelated words following procedures outlined by Green and Swets (1966) and using tables provided by Hochhaus (1972). An analysis of variance applied to the $d^{\prime}$ scores indicated highly significant $(p<.001)$ effects for both age $[F(1,182)=15.86]$ and instructions $[F(1,182)=19.32]$. Post hoc comparison using the Neuman-Keuls procedure indicated that the association and neutral conditions differed significantly $(p<.05)$ at both age levels. The difference between the association and repetition conditions was significant for the adults $(p<.05)$ and of borderline significance $(.10>p>.05)$ for the children. The difference between the neutral and repetition conditions was of borderline significance for the children $(.10>\mathrm{p}>.05)$ but did not approach significance for the adults.

From the self-reports of the adults in the neutral condition, we identified nine Ss who indicated frequent extralist IAR production and 18 Ss who reported no use of associative processes. A comparison of these subgroups showed no difference in false recognitions of associates relative to unrelated words but a very large superiority by the IAR producers in recognition memory accuracy, as reflected by d' scores $(p<.01)$.

The above data indicate that the memory encoding modifications produced by the associative instructions were highly beneficial to RM and that repetition instructions were detrimental (for the children), or at least not helpful (for the adults). Such findings seem contrary to expectations based on a frequency analysis of RM as proposed by Underwood and Freund (1968). According to that analysis, the S's decision in the usual RM test is based on the perceived situational frequency associated with the test item, such that the greater that frequency, the more likely is the $S$ to judge the item as old. Since the perceived situational frequency count is assumed to increase with increased item rehearsal, one might expect that count to be highest under the repetition instructions. Further consideration will be given this issue in the later General Discussion section.
Table 2

Mean Number of "Old" Judgments in Experiment

\begin{tabular}{llrccc}
\hline & & \multicolumn{4}{c}{ Test List Condition } \\
\cline { 3 - 6 } $\begin{array}{llcc}\text { Encoding } \\
\text { Instructions }\end{array}$ & & $\begin{array}{c}\text { Old } \\
\text { Words }\end{array}$ & $\begin{array}{c}\text { Asso- } \\
\text { ciates }\end{array}$ & $\begin{array}{c}\text { Rhym- } \\
\text { ing } \\
\text { Words }\end{array}$ & $\begin{array}{c}\text { Unre- } \\
\text { lated } \\
\text { Words }\end{array}$ \\
\hline \multirow{5}{*}{ Association } & Mean & 11.25 & 3.93 & 1.54 & 1.14 \\
& SD & 3.26 & 2.83 & 1.99 & 1.74 \\
Neutral & Mean & 8.64 & 4.28 & 2.32 & 2.54 \\
& SD & 2.90 & 3.04 & 2.25 & 2.30 \\
Repetition & Mean & 10.18 & 3.32 & 1.93 & 2.00 \\
& SD & 3.28 & 2.65 & 2.36 & 2.04 \\
& & & College & Students & \\
\multirow{5}{*}{ Association } & Mean & 13.40 & 2.54 & 1.16 & .94 \\
& SD & 2.33 & 2.91 & 2.03 & 1.47 \\
Neutral & Mean & 11.05 & 3.94 & 2.16 & 2.16 \\
& SD & 3.36 & 3.32 & 2.05 & 2.46 \\
Repetition & Mean & 10.92 & 2.44 & 1.89 & 1.69 \\
& SD & 3.07 & 3.34 & 2.58 & 2.34 \\
\hline
\end{tabular}

\section{EXPERIMENTS II, III, AND IV}

Recall by third and fourth graders was examined in Experiment II either $1 \mathrm{~min}$ or $90 \mathrm{~min}$ following presentation of the word under the same three learning instructions as in Experiment I. Our concern was with the degree to which the instructional effects obtained for RM would be paralleled for FR and possible interactions of instructions with retention interval. Experiment III replicated Experiment II but with fifth-grade children. Experiment IV differed from those two studies only in that Ss were adults and that a 24-h retention interval was substituted for the 90-min interval used in Experiments II and III.

\section{Method}

Subjects. The Ss were 54 third graders and 60 fourth graders for Experiment II and 108 fifth graders for Experiment III, all of whom attended a public elementary school in Evanston. In Experiment IV, 114 Northwestern University students enrolled in an introductory psychology class served as Ss.

Design and Procedure. In each study all Ss were presented the words used in Experiment I under the same three instructional conditions (association, neutral, and repetition) and using the same procedures. Within each instructional condition, approximately half of the Ss were tested for FR 1 min and half for either $90 \mathrm{~min}$ (Experiments II and III) or $24 \mathrm{~h}$ (Experiment IV) following list presentations. The FR test was self-paced and Ss simply were asked to write down the words they remembered without concern for precise spelling.

\section{Results and Discussion}

In analyzing the FR data, 2 of the 40 to-be-remembered items were excluded. The word MAN was excluded because it was used in the instructions given in the association and repetition conditions. The word BOY also was excluded because of its associative relationship to MAN. Thus, the functional list in the 
Table 3

Mean Free Recall in Experiments II, III, and IV

\begin{tabular}{|c|c|c|c|c|c|}
\hline \multirow[b]{2}{*}{$\begin{array}{c}\text { Experi- } \\
\text { ment }\end{array}$} & \multirow{2}{*}{$\begin{array}{l}\text { Reten- } \\
\text { tion } \\
\text { Interval }\end{array}$} & & \multicolumn{3}{|c|}{ Encoding Instructions } \\
\hline & & & $\begin{array}{l}\text { Associa- } \\
\text { tion }\end{array}$ & Neutral & $\begin{array}{c}\text { Repeti- } \\
\text { tion }\end{array}$ \\
\hline \multirow{2}{*}{$\begin{array}{l}\text { II } \\
\text { Grades } \\
3 \text { and } 4\end{array}$} & $1 \mathrm{Min}$ & $\begin{array}{l}\text { Mean } \\
\text { SD }\end{array}$ & $\begin{array}{l}5.10 \\
2.08\end{array}$ & $\begin{array}{l}4.68 \\
2.29\end{array}$ & $\begin{array}{l}4.21 \\
1.99\end{array}$ \\
\hline & $90 \mathrm{Min}$ & $\begin{array}{l}\text { Mean } \\
\text { SD }\end{array}$ & $\begin{array}{l}3.79 \\
1.99\end{array}$ & $\begin{array}{l}4.63 \\
1.67\end{array}$ & $\begin{array}{l}2.58 \\
1.39\end{array}$ \\
\hline \multirow[t]{2}{*}{$\begin{array}{l}\text { III } \\
\text { Grade } 5\end{array}$} & $1 \mathrm{Min}$ & $\begin{array}{l}\text { Mean } \\
\text { SD }\end{array}$ & $\begin{array}{l}7.72 \\
2.44\end{array}$ & $\begin{array}{l}6.66 \\
1.71\end{array}$ & $\begin{array}{l}7.55 \\
3.11\end{array}$ \\
\hline & $90 \mathrm{Min}$ & $\begin{array}{l}\text { Mean } \\
\text { SD }\end{array}$ & $\begin{array}{l}6.16 \\
1.95\end{array}$ & $\begin{array}{l}7.72 \\
3.51\end{array}$ & $\begin{array}{l}5.72 \\
2.89\end{array}$ \\
\hline \multirow[t]{2}{*}{$\begin{array}{l}\text { IV } \\
\text { Adults }\end{array}$} & $1 \mathrm{Min}$ & $\begin{array}{l}\text { Mean } \\
\text { SD }\end{array}$ & $\begin{array}{r}14.16 \\
4.02\end{array}$ & $\begin{array}{r}13.10 \\
4.59\end{array}$ & $\begin{array}{r}10.79 \\
2.94\end{array}$ \\
\hline & $24 \mathrm{H}$ & $\begin{array}{l}\text { Mean } \\
\text { SD }\end{array}$ & $\begin{array}{l}8.21 \\
3.36\end{array}$ & $\begin{array}{l}7.58 \\
4.68\end{array}$ & $\begin{array}{l}4.84 \\
2.69\end{array}$ \\
\hline
\end{tabular}

three FR experiments consisted of 38 items.

The mean FR scores are shown in Table 3. For Experiment II highly significant effects were found both for instructions $[F(2,90)=7.07, p<.01]$ and for retention interval $[F(1,90)=7.50, p<.01]$. Interpretation of these main effects is somewhat complicated by the suggestion of an interaction between them, although that interaction is not significant $[F(2,90)=1.40, p>.10]$. Specifically, after $1 \mathrm{~min}$ the association and neutral conditions were nearly equal, with the repetition condition considerably lower. However, both the association and neutral conditions showed marked forgetting (31\% and 51\% losses, respectively), whereas virtually no forgetting (a 4\% loss) occurred for the neutral condition. For the fifth graders in Experiment II, a similar pattern of results was found and, in this case, the interaction between instructions and retention interval was significant $[F(2,96)=3.81$, $\mathrm{p}<.05]$, whereas neither main effect reached significance. Complicating matters is the fact that under neutral instructions performance increased by $20 \%$ over time. Nevertheless, the two experiments taken together suggest that the $\mathrm{Ss}$, when left to their own devices, employed encoding operations that were more resistant to forgetting than were the operations employed under either the association or repetition condition.

In Experiment IV, which used adults and a 24-h retention interval in place of $90 \mathrm{~min}$, significant effects were found both for instructions $[\mathrm{F}(2,102)=3.99$, $\mathrm{p}<.05]$ and retention interval $[\mathrm{F}(1,102)=63.98$, $\mathrm{p}<.0011$. At both retention intervals, the association instructions produced the best FR, with the neutral condition only slightly lower. The repetition instructions were least effective, particularly for the 24-h condition.

Also of interest was performance in relation to the serial position of items. To the extent that encoding instructions were followed, one would expect a greater primacy effect for the neutral condition than for the remaining conditions. That is, if rehearsal time was occupied with producing extralist IARs or repetitions of just presented items, then little opportunity would exist for rehearsal of items presented earlier. To examine this prediction, performance was plotted separately for the first 7 items, the next 24 items, and the last 7 items. The results for Experiment II are shown in Fig. 1 in terms of percentages of possible recall and clearly support the expectation of a greater primacy effect for the neutral condition. A further point of interest here is the fact that forgetting appears to be much greater for items in the middle and recency positions of the list. In fact, almost no forgetting occurred for items in the primacy position for any of the three instructions conditions.

Similar results occurred in Experiment III to the extent that the neutral condition showed the greatest primacy effect, no loss from $1 \mathrm{~min}$ to $90 \mathrm{~min}$ occurred for primacy items, and the greatest loss occurred for recency items. This same pattern of results occurred in Experiment IV, but the various positional differences were less pronounced.

\section{GENERAL DISCUSSION}

The results of Experiment I indicate a highly beneficial effect on RM of instructions to produce IARs during memory encoding, both for adults and for

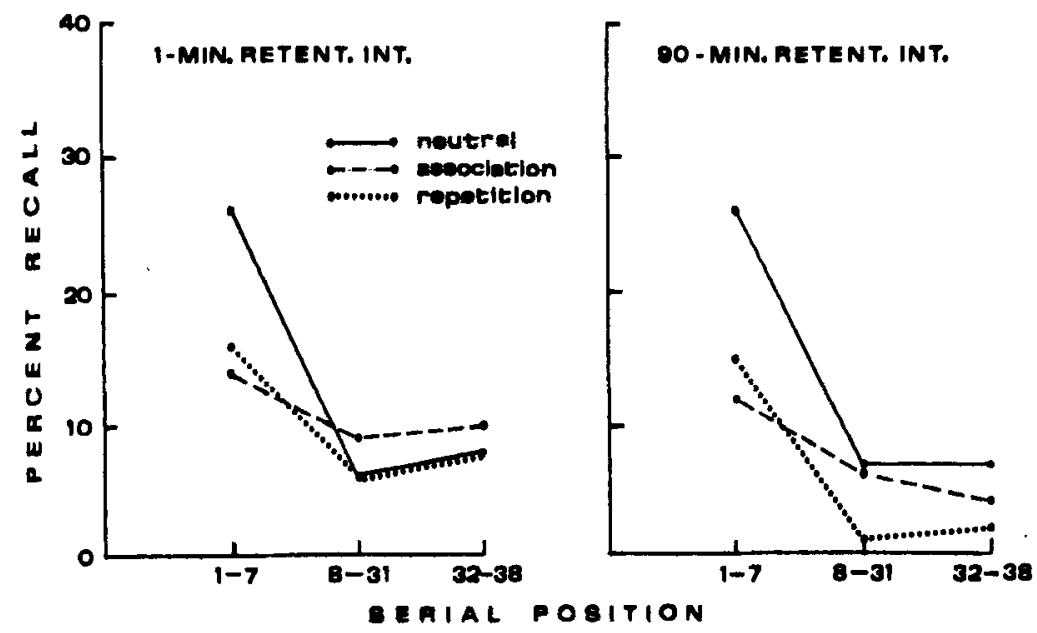

Fig. 1. Free recall in Experiment II as a function of encoding instructions, retention interval, and serial position of presented items. 
children. It appears, however, that these instructions did not result in equivalent encoding modifications at the two age levels. The frequency of false recognitions of associates relative to unrelated words appeared to be higher under association than under neutral instructions for the children but not for the adults. Taken alone, these data suggest that the association instructions resulted in greater IAR production by the children but had little or no effect on adult encoding. This conclusion is not plausible in light of the fact that association instructions facilitated general recognition accuracy at both age levels, as pointed out above. Thus, the adults in the association condition obviously were led to do something differently. One possible explanation of the differences in associative false recognitions is that the explicit instructions to produce IARs sensitized the older Ss to such false recognitions. That is, adult Ss in the association instructions condition may have been more likely to "catch on" and take greater care to avoid falsely identifying the associates as old words. Another possibility is that under the neutral instructions the aduits are simply much more likely than are the children to produce strong natural language associates. Thus, instructions to associate would not result in as substantial an increase in the frequency with which such strong associates occurred. The real difference in encoding produced by the association instructions then would not be in the frequency of strong associates as IARs, but in their diversity or in some other quality that, in a fashion not yet understood, would facilitate accurate recognition decisions.

As mentioned earlier, frequency theory applied to RM leads to an expectation of greater RM accuracy for those Ss who rehearsed items most. Accordingly, one might expect greatest accuracy for the repetition condition, assuming that instructions to "say the words over and over again to yourself" were followed rather closely and that each such implicit pronunciation contributed one "frequency count" to the subjective frequency for that item (see Ekstrand, Wallace, \& Underwood, 1966, for a clarification of this notion). However, performance was poorest under the repetition instructions. Thus, it appears likely that with very high rates of pronunciation (either implicit or explicit) each pronunciation does not contribute to accumulated subjective frequency as much as with a slower rehearsal rate or when rehearsal is distributed. To pursue this point further, we administered the RM task both to college students and to sixth graders under overt repetition instructions. The correlations obtained suggested essentially no relationship between number of overt repetitions and RM performance under such conditions.

The question that remains unanswered by our data concerns the mechanism by which phenomenal frequency fails to accumulate under the conditions of massed and speeded rehearsal obtaining for the repetition condition. The problem here bears some similarity to that faced by Underwood $(1969 a, b)$ in discussing the retardation in accumulation of phenomenal frequency when presented items were massed rather than distributed within a list. Two possibilities were suggested by Underwood which seem applicable here also. One is that the high-speed repetition produced a form of verbal satiation. The second is that such repetition effectively transforms the word such that it is perceived as a different word (e.g., CANOECANOECANOE).

A second point suggested by the data (particularly by the RM superiority of the association condition to the neutral condition) is that verbal associations play a much greater role in RM than has been generally assumed. We propose that the IAR in this case provides a discriminative cue that, together with the perceived frequency cue, leads to better performance than if the frequency cue alone is used. This assumes, first, that, even under the association instructions, a substantial build-up of subjective frequency occurs through perceiving and rehearsal. For example, the $S$ may say the word to himself, produce one or more IARs, then go back to the word-searching, perhaps, for additional IARs. Thus, at the time of testing, difference in perceived situation frequency between most old and new items is sufficiently great to be useful in making the recognition decision. However, when an old word is presented, the $\mathrm{Ss}$ in the association condition are more likely to be reminded of the IAR that they had produced during learning. Whatever doubt they had on the basis of frequency alone would then be resolved, resulting in better performance than for Ss in the neutral condition.

Another possible explanation of the superior performance of the association group is more compatible with the frequency theory analysis. That is, the subjective frequency of old items may be augmented by the occurrence of these items as IARs to other words in the list. Thus, if Ss instructed to produce associates did in fact produce a number of the to-be-remembered items as IARs, then perceived frequency for those items may have been greater for the Ss in the association condition. Although an inspection of the relationship among to-be-remembered items does not suggest this as a likely possibility, it is one that deserves investigation.

The FR data parallel the RM data in that performance is markedly and uniformly poorer under repetition than under association instructions. They differ, however, in that no consistent superiority of the association over the neutral instructions was found. A rather intriguing finding was the strong suggestion in Experiments II and III of an interaction between instructions and retention interval, reflecting a tendency toward more rapid forgetting for the association and repetition conditions in contrast to the neutral condition, in which Ss were left to their own devices. In contrast, no such interaction was suggested by the adult data of Experiment IV. Two differences existed among the experiments that might account for the disparity in results. First, the retention 
interval was much longer in Experiment IV than in Experiments II and III. Perhaps the differential effects of such instructions are relatively short-lived. The second difference, the fact that adults were used in Experiment IV and children in Experiments II and III, offers more interesting and plausible possibilities. The data concerning false recognitions of associates suggest that the effects of the encoding instructions on actual encoding operations probably were not the same for the adults and the children. This conclusion is supported also by the analysis of FR performance as a function of list position. Among the third and fourth graders, performance on items in the primary position was far superior for the neutral condition compared with the others. A similar but much smaller difference occurred for the adults in Experiment IV. Thus, the differential effects of the three types of instructions on encoding operations of adults and children may well account for the occurrence of an Instructions by Retention Interval interaction with the children but not with the adults.

The serial position data are interesting in two other respects. First, although the primacy effect was greater under neutral instructions (as anticipated), some such effect occurred under the remaining conditions at all age levels. Evidently, even the younger children departed from the repetition and IAR production imposed on them to sneak in a few rehearsals of earlier items. Second, the tendency of Ss in Experiments II and III to retain primacy items while losing later ones over the 90-min period is striking. This interaction between serial position and retention occurred in all three FR experiments, but it is most interesting in the case of the third and fourth graders (Experiment II). Note that there is, at best, only a very slight recency effect at that age level, indicating, presumably, little or no tendency to hold recency items in short-term memory by active rehearsal during the 1-min retention interval. Moreover, the loss over the $90 \mathrm{~min}$ appears to be much greater even from the middle portion of the list than from the primacy positions. It appears that, for reasons not explicated by our data, the processes by which the earliest items were encoded are more effective in resisting forgetting than are those used with later items.

Finally, it is interesting to compare the data in Tables 2 and 3 from a developmental viewpoint. Note that, whereas RM increases only slightly, though significantly, from Grades 3 and 4 to adulthood, there is a threefold increase in FR over the same period. Recent research with kindergarten through fourth-grade children (Hall \& Pressley, 1973) showed no increase in RM but a substantial increase in FR with age. These data suggest that processes necessary for accurate RM develop more rapidly than do those necessary for FR. Both the locus (encoding vs retrieval) and the nature of such differences remain unknown.

\section{REFERENCES}

Anisfeld, M., \& Knapp, M. Association, synonymity, and directionality in false recognition. Journal of Experimental Psychology, 1968, 77, 171-179.

Ekstrand, B. R., Wallace, W. P., \& Underwood, B. J. A frequency theory of verbal discrimination learning. Psychological Review, 1966, 73, 566-578.

Green, D. M., \& Swets, J. A, Signal detection theory and psychophysics. New York: Wiley, 1966. Pp. 1-147, 337-346.

$\mathrm{Hall}, \mathrm{J}$. W. Effects of three variations in learning instructions on children's word-recognition performance. Journal of Educational Psychology, 1969, 60, 461-464.

Hall, J. W., \& Halperin, M. S. The development of memory encoding processes in young children. Developmental Psychology, 1972, 6, 181.

Hall, J. W., \& Pressley, G. M. Free recall and recognition mem ory in young children. Paper presented at the annual meeting of the Psychonomic Society, St. Louis, November 1973.

Hochhaus, L. A table for the calculation of $\mathrm{d}^{i}$ and $\beta$. Psychological Bulletin, 1972, 77, 375-376.

Kimble, G. A. Mediating instructions. Journal of Experimental Psychology, 1968, 76, 269-272.

Underwood, B. J. Attributes of memory. Psychological Review, $1969 a, 76,559-573$

Underwood, B. J. Some correlates of item repetition in free-recall learning. Joumal of Verbal Learning \& Verbal Behavior, $1969 \mathrm{~b}, 8,83-94$.

Underwood, B. J. False recognition produced by implicit verbal responses. Journal of Experimental Psychology, 1965, 70, 122-129.

Underwood, B. J.. \& Freund, J. S. Errors in recognition learning and retention. Journal of Experimental Psychology, 1968, 78, 55-63.

(Received for publication November 14, 1973; revision received February 22, 1974.) 